\title{
A Brief History, Status, and Perspective of Modified Oligonucleotides for Chemotherapeutic Applications
}

Modification of oligonucleotides for drug applications has a very short history (for highlights see Table 4.1.1 and Table 4.1.2). Intensive efforts to modify short strands of nucleic acids to enhance their properties as drug candidates began in earnest in the late 1980s. The notion that oligonucleotides could be made into drugs along with the discovery and development of two essential enabling technologiesautomated DNA sequencing (Connell et al., 1987) and commercial automated oligonucleotide synthesis and purification in the early 1980s — set the stage for oligonucleotide drug discovery (reviewed by Zon, 1993). Subsequently, oligonucleotide medicinal chemistry and pharmacology, which form the basis of structure-activity relationship studies, have been highly developed in the process of converting oligonucleotides into drugs. Before this, little value was given to synthetically changing the structure of short strands of DNA or RNA except for some early modifications primarily directed to enhance structural studies and diagnostic applications. Now great interest in making drugs out of oligonucleotides has spurred intense structure-activity/property relationship (SAPR) studies to optimize drug properties (Cook, 1998a,b).

Given that oligonucleotides are gene-based materials (or informational materials; Cohen, 1991) and considering the emergence of genomic target selection, which is also gene- based, it is surprising that it has taken so long for the drug discovery community to recognize the potential value of modified oligonucleotides as drugs. However, when traditional medicinal chemists first consider modifying oligonucleotides, they are confronted with a number of daunting chemical, biophysical, and biochemical properties of oligonucleotides (Table 4.1.3), which has surely slowed progress in this area. In addition to the need to apply novel ligands to drug discovery, the nucleic acid targets that serve as receptors, particularly RNA molecules, are novel as well. In spite of the early difficulties in exploring the use of oligonucleotides as drugs, however, much progress has been made in recent years. The first antisense oligonucleotide drug, Vitravene, was recently approved by the Food and Drug Administration (FDA) for treating cytomegalovirus retinitis in AIDS patients, and several additional oligonucleotides are in late phase II and III clinical studies for anti-cancer and antiinflammatory indications (Table 4.1.4).

\section{OVERVIEW OF BASE PAIRING AND GENE EXPRESSION}

A single strand of nucleic acid has a polymeric sugar-phosphate backbone with ribofuranosyl (in RNA) or deoxyribofuranosyl (in DNA) residues connected at the $3^{\prime}$ and $5^{\prime}$ hydroxyls by phosphoric acid to form phosphodiester linkages. Each sugar residue has one of

Table 4.1.1 Historical Listing of Oligo- and Polynucleotides as Therapeutic Agents

\begin{tabular}{ll}
\hline Milestone & References \\
\hline DNA alkylating agents & Belikova et al. (1967); Summerton (1979) \\
Poly(rI) • poly(rC) & De Clercq et al. (1969) \\
Macromolecular antimetabolites & Chandra and Bardos (1972); reviewed by \\
"Antitemplates" & Bardos and Ho (1978) \\
Antisense oligonucleotides (targeting RNA) & See Table 4.1.2 \\
Heterocycle modified oligonucleotides: & Alderfer et al. (1985) \\
prodrugs for nucleosides & \\
Antigene oligonucleotides: triple strand & Moser and Dervan (1987); LeDoan et al. \\
formers & $(1987)$ \\
Aptamers & Ellington and Szostak (1990); Tuerk and Gold \\
Sense approach & $(1990)$ \\
\hline
\end{tabular}


Table 4.1.2 Highlights of the Development of Chemotherapeutic Oligonucleotides

\begin{tabular}{|c|c|}
\hline Milestone & References \\
\hline Antisense experiments in cell culture & $\begin{array}{l}\text { Stephenson and Zamecnik (1978); Zamecnik } \\
\text { and Stephenson (1978) }\end{array}$ \\
\hline Automated synthesis, protocols, reagents & Merrifield, Letsinger, Caruthers (1962-1987) \\
\hline Methylphosphonate oligonucleotides & Ts'o et al. (1987) \\
\hline Phosphorothioates & Eckstein, Stec, Zon (1967-1981) \\
\hline Ribozymes & Cech (1986); Altman (1989) \\
\hline $\begin{array}{l}\text { Initiation of first clinical trial; first report of } \\
\text { clinical efficacy }\end{array}$ & Isis Pharmaceuticals (1992-1994) \\
\hline $\begin{array}{l}\text { Twenty five oligonucleotides entered into } \\
\text { clinical development }\end{array}$ & (1992-present; see Table 4.1.4) \\
\hline $\begin{array}{l}\text { First New Drug Application (NDA) for an } \\
\text { antisense oligonucleotide }\end{array}$ & Isis Pharmaceuticals (April 1998) \\
\hline First approved antisense oligonucleotide drug & Isis Pharmaceuticals (August 1998) \\
\hline
\end{tabular}

five types of heterocycles (nucleobases) attached at the $\mathrm{C1}^{\prime}$ position of either the deoxyribofuranosyl or ribofuranosyl sugar. These heterocycles are the purines (guanine and adenine) and the pyrimidines (cytosine and thymine, with uracil replacing thymine in RNA).

Complementary DNA describes a chemical complex of two strands of deoxyribonucleic acid that are bound together by WatsonCrick base-pair hydrogen bonding. This "essences of life" bonding specifies that guanine in one DNA strand specifically binds to cytosine in the other strand, and that adenine in one DNA strand specifically binds to thymine in the other strand (Fig. 4.1.1). In RNA, uracil specifically binds to adenine. A sequence (or a specific ordering of nucleobases) of an RNA or a DNA strand will bind specifically (hydrogen bond) to another sequence only if the nucleobases match up (base pair). The strands are then said to be complementary to one another.

The complementary DNA strands twist into a helical motif with one strand having its bases ordered in the $3^{\prime}$ to $5^{\prime}$ direction and the other strand having its bases ordered in the opposite direction $\left(5^{\prime}\right.$ to $\left.3^{\prime}\right)$. This is referred to as antiparallel orientation (Fig. 4.1.2). The doublestranded DNA (dsDNA) serves as the template for synthesis of either complementary DNA molecules, to provide a process of self-replication, or complementary RNA molecules (from the sense strand) for the process of transcription. The complementary DNA strand, referred to as the antisense strand, is itself rarely transcribed to give an RNA molecule.

Table 4.1.3 Chemical, Biochemical, and Biophysical Properties of First-Generation Oligonucleotides

\begin{tabular}{ll}
\hline Parameter & Property \\
\hline Molecular weight & High (20- to 25-mers, MW 7000 to 9000) \\
Charge & Highly negative (19 to 24 charges) or neutral \\
Chirality in backbone & $\mathrm{P}=\mathrm{S}$, Me-P, N-P \\
Instabilities & Biological and chemical (nucleases, pH, depurination, dethiation) \\
Solubility & Insoluble in common organic solvents depending on backbone \\
& modification (P=S versus Me-P) ${ }^{a}$ \\
Crystalline? & No \\
Ease of synthesis & Complex synthesis of reactive monomers \\
& Unfamiliarity with instrument synthesis of oligomers \\
& Purification by ion exchange chromatography \\
& Analysis and characterization atypical \\
\hline${ }^{a}$ Me-P, methylphosphonate; N-P, phosphoramidate; P=S, phosphorothioate.
\end{tabular}


Table 4.1.4 Oligonucleotides Entered into Clinical Development ${ }^{a}$

\begin{tabular}{|c|c|c|c|c|}
\hline Oligonucleotide & Molecular target & $\begin{array}{l}\text { Disease } \\
\text { indications }\end{array}$ & Status $^{b}$ & Sponsor \\
\hline ISIS 2105 & $\begin{array}{l}\text { HPV } 6 \text { and } 11 \text { E2 } \\
\text { genes product }\end{array}$ & Genital warts & Terminated & Isis \\
\hline ISIS 2922 & HCMV IE gene-2 & CMV retinitis & $\begin{array}{l}\text { NDA approved } \\
\text { (August 1998) }\end{array}$ & Isis/Ciba Vision \\
\hline ISIS 2302 & $\begin{array}{l}\text { Intercellular } \\
\text { adhesion } \\
\text { molecule } \\
\text { (ICAM-1) }\end{array}$ & $\begin{array}{l}\text { Renal allograft, } \\
\text { rheumatoid } \\
\text { arthritis, Crohn's } \\
\text { disease, } \\
\text { ulcerative colitis, } \\
\text { psoriasis }\end{array}$ & $\begin{array}{l}\text { III, Crohn's; } \\
\text { II for others }\end{array}$ & $\begin{array}{l}\text { Isis/Boehringer } \\
\text { Ingleheim }\end{array}$ \\
\hline $\begin{array}{l}\text { ISIS 3521/CPG } \\
\quad 64128 \mathrm{~A}\end{array}$ & $\begin{array}{l}\text { Protein kinase } \\
\text { C- } \alpha\end{array}$ & Cancer & II & Isis/Novartis \\
\hline $\begin{array}{l}\text { ISIS 5132/CPG } \\
69846 \mathrm{~A}\end{array}$ & c-raf kinase & Cancer & II & Isis/Novartis \\
\hline ISIS 13312 & HCMV IE gene & CMV retinitis & $\mathrm{I} / \mathrm{II}$ & Isis \\
\hline ISIS 5320 & Gp120 & AIDS & Terminated & Isis \\
\hline ISIS 2503 & Ha-ras & Cancer & I & Isis \\
\hline GEM-91 & gag gene & AIDS & Terminated & Hybridon \\
\hline GEM-92 & gag gene & AIDS & I & Hybridon \\
\hline GEM-132 & UL36 and UL37 & CMV retinitis & I & Hybridon \\
\hline GEM-231 & Protein kinase A & Cancer & II & Hybridon \\
\hline OL(1)p53 & p53 & Cancer & Terminated & Lynx/Inex \\
\hline \multirow[t]{2}{*}{ LR-3280 } & $\mathrm{c}-m y c$ & Restenosis & Terminated & Lynx/Inex \\
\hline & $\mathrm{c}-m y b$ & Cancer & Terminated & Lynx/Inex \\
\hline GPs 0193 & gag gene & AIDS & Terminated & Chugai \\
\hline Zintevir & HIV integrase & AIDS & $\mathrm{I} / \mathrm{II}$ & Aronex \\
\hline G3139 & Bcl-2 & Cancer & II & Genta \\
\hline GPI-2A & gag gene & AIDS & Terminated & $\begin{array}{l}\text { Novopharm } \\
\text { Biotech }\end{array}$ \\
\hline GTI 2040 & $\begin{array}{l}\text { Ribonucleotide } \\
\text { reductase R2 } \\
\text { subunit }\end{array}$ & Cancer & I & GeneSense \\
\hline MG-98 & DNA methylase & Solid tumors & I & MethylGene \\
\hline Resten-NG & $\mathrm{c}-m y c$ & $\begin{array}{l}\text { Restenosis and } \\
\text { proliferative } \\
\text { diseases }\end{array}$ & I & AVI BioPharma \\
\hline Heptazyme & IRES region & Hepatitis $\mathrm{C}$ virus & I & $\begin{array}{l}\text { Ribozyme } \\
\text { Pharmaceuticals }\end{array}$ \\
\hline Angiozyme & $\begin{array}{l}\text { Vascular } \\
\text { endothelial } \\
\text { growth factor } \\
\text { receptor }\end{array}$ & $\begin{array}{l}\text { Anti- } \\
\text { angiogensis } \\
\text { (cancer) }\end{array}$ & I & Ribozyme \\
\hline CPG-X & Immune system & Hepatitis B & I & $\mathrm{CpG}$ \\
\hline
\end{tabular}

${ }^{a}$ Abbreviations: E, early gene; HCMV, human cytomegalovirus; HPV, human papillomavirus; IE, immediate early gene; IRES, internal ribosomal entry site; NDA, New Drug Application; UL, unique long.

$b_{\mathrm{I}}$ II, and III indicate phase of clinical trials at time of printing.

Synthesis of Modified

Oligonucleotides and Conjugates 


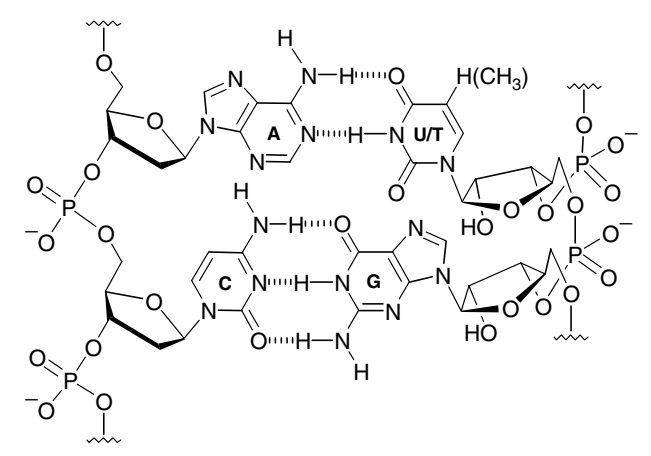

Figure 4.1.1 Watson-Crick hydrogen-bonding (base-pairing) rules ( $G$ to $C, A$ to $U$ or $T$ ).

The transcribed RNA molecules, in turn, serve as the templates that allow the ordering of the amino acids within the polypeptide chain of proteins, during the process of translation. Translation is an appropriate term because the nucleotide sequence information (language) of nucleic acids is translated into the amino acid sequence (language) of protein. The complete process-DNA makes RNA makes proteinhas been referred to as the central dogma of molecular biology. A more common term for the process is gene expression. Thus, the two stages of gene expression are transcription (the conversion of DNA to RNA) and translation (the conversion of RNA to proteins). DNA also self-replicates to maintain an organism's genome. Furthermore, regulation of gene expression in living organisms involves extensive recognition and binding to specific nucleic acid sequences by nucleic acid-binding proteins.

\section{INFORMATIONAL DRUG DISCOVERY APPROACHES AND THEIR SUCCESS}

Disease states (genetic, oncogenic, or infective) are typically a result of the production of abnormal proteins, the end-stage product of gene expression. Thus, it is not surprising that drug discovery has historically focused on interfering with the functions of the abnormal proteins rather than on preventing abnormal protein formation - treating the disease symptoms rather than the cause. In contrast, treatment approaches involving informational chemicals, such as oligonucleotides, attempt to prevent the formation (gene expression) of abnormal protein by targeting DNA, RNA, or regulatory proteins that are required for transcription and translation of the abnormal protein. Having a set of binding rules (Watson-Crick base-pairing rules) that allows one to rapidly and precisely select a molecule to synthesize that will inhibit gene expression at the DNA or RNA level, and that offers exquisite specificity for its receptor, is unique in the history of drug research. Thus, the employment of informational drugs to complement genomic target validation in modern drug discovery is revolutionary.

Several discovery approaches are being pursued that employ the encoded information of modified oligonucleotides as the drug agent (Tables 4.1.1 and 4.1.2). In the process of transcription, complementary RNA (message RNA or mRNA) is derived from the sense DNA strand by Watson-Crick base-pair recognition and binding. The antisense approach targets the initial sense complementary RNA strand (primary transcript) as well as many downstream sites that are available as RNA is metabolized in the process of protein production (e.g., splicing, transport, translation; Fig. 4.1.2).

A strict definition of the antisense approach describes the inhibition of gene expression through targeting of a predetermined sequence in an RNA. There are several types of antisense approaches, which may be differentiated on the basis of their modes of action (Fig. 4.1.2). Antisense oligonucleotides primarily operate by sequence-specific binding to the targeted RNA. The resultant heteroduplex recruits a ubiquitous endonuclease, ribonuclease $\mathrm{H}$ (RNase H), to cleave the targeted RNA strand. Other potential antisense modes of action are by direct sequence-specific binding of the oligonucleotides to the targeted RNA (or merely occupying a site on the RNA) such that the function of essential RNA-binding proteins is disrupted or that secondary structure required for gene expression of the RNA is disrupted. A variety of distinct sites in the intermediary metabolism of RNA can potentially be targeted by antisense oligonucleotides with RNase $\mathrm{H}-$ dependent or -independent modes of action depicted in Figure 4.1.2. 


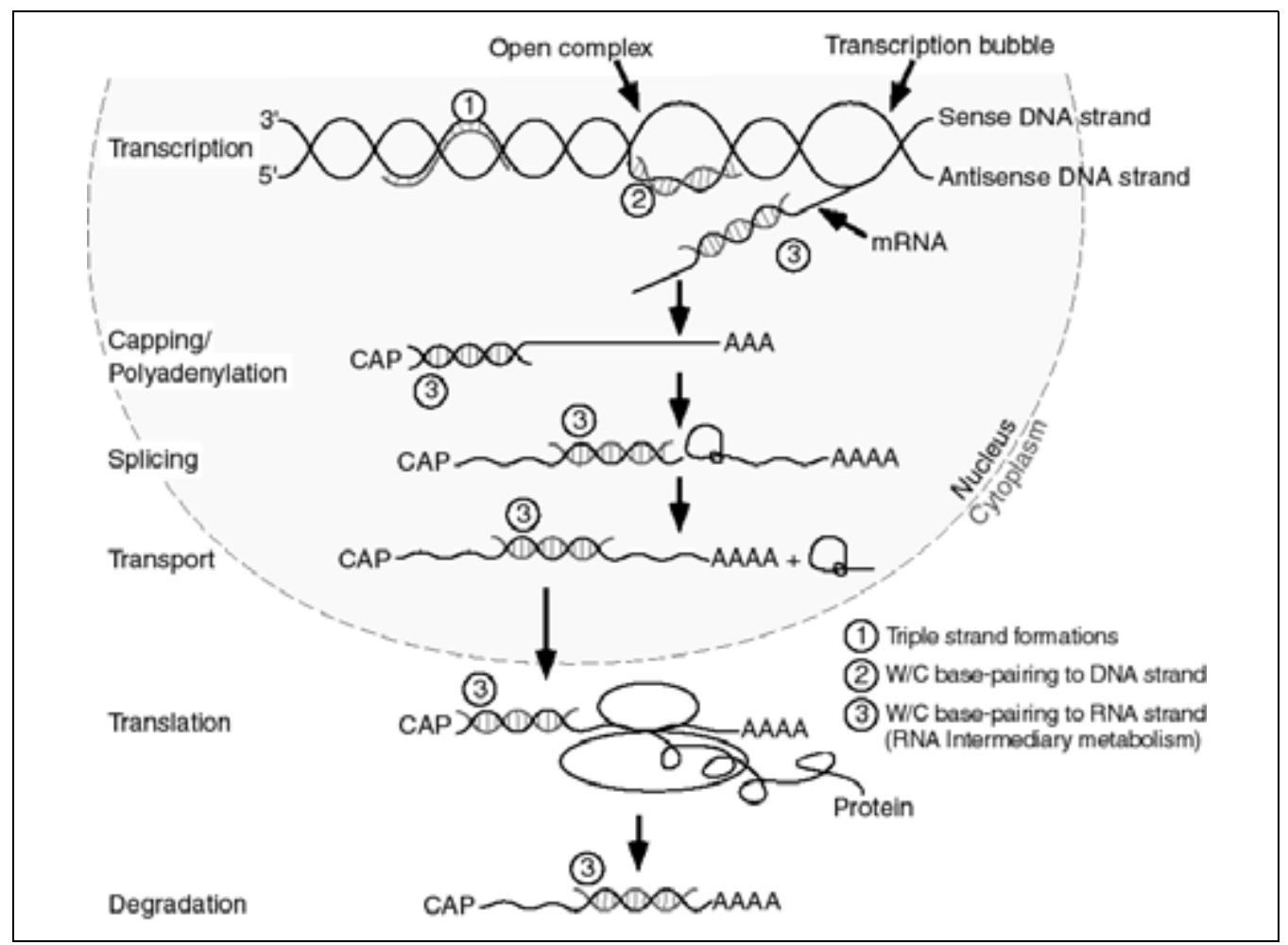

Figure 4.1.2 Informational drug-targeting sites. CAP, $\mathrm{m}^{7} \mathrm{Gppp}$; W/C, Watson-Crick.

RNase $\mathrm{L}$, like RNase $\mathrm{H}$, is another cellular nuclease that cleaves RNA. Its endonucleolytic cleavage is triggered by binding to $\left(2^{\prime}-5^{\prime}\right)$ linked polyadenylic sequences (Fig. 4.1.3). Torrence and co-workers have conjugated the RNase L activating moiety to oligonucleotides to provide sequence-specific cleavage of targeted RNA (Torrence et al., 1994).

Ribozymes are RNA molecules with catalytic RNA-cleaving activity (Cech, 1986) and thus represent another type of antisense oli- gonucleotide. These are typically much longer RNA molecules that contain both a catalytic region (which can cleave another RNA segment) and an adjacent sequence or two sequence arms that allow Watson-Crick base-pair binding to the target. A variety of ribozymes have been described that differ primarily in their threedimensional structures and lengths (reviewed by Rossi, 1998). The sequence-specific cleavage of a predetermined RNA target is accomplished without assistance from any protein.

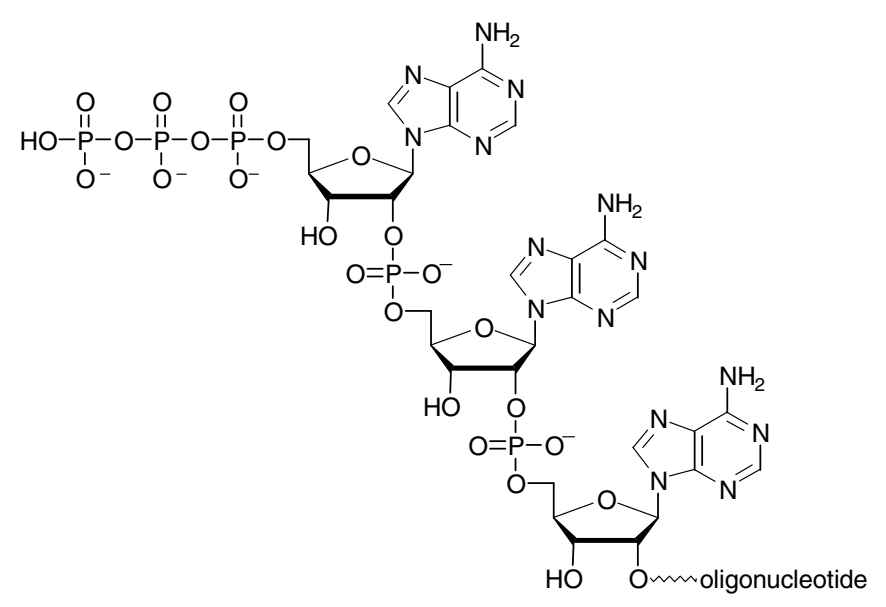

Figure 4.1.3 $\left(2^{\prime}-, 5^{\prime}\right)$-Adenylic oligonucleotides.

Synthesis of Modified Oligonucleotides and Conjugates 


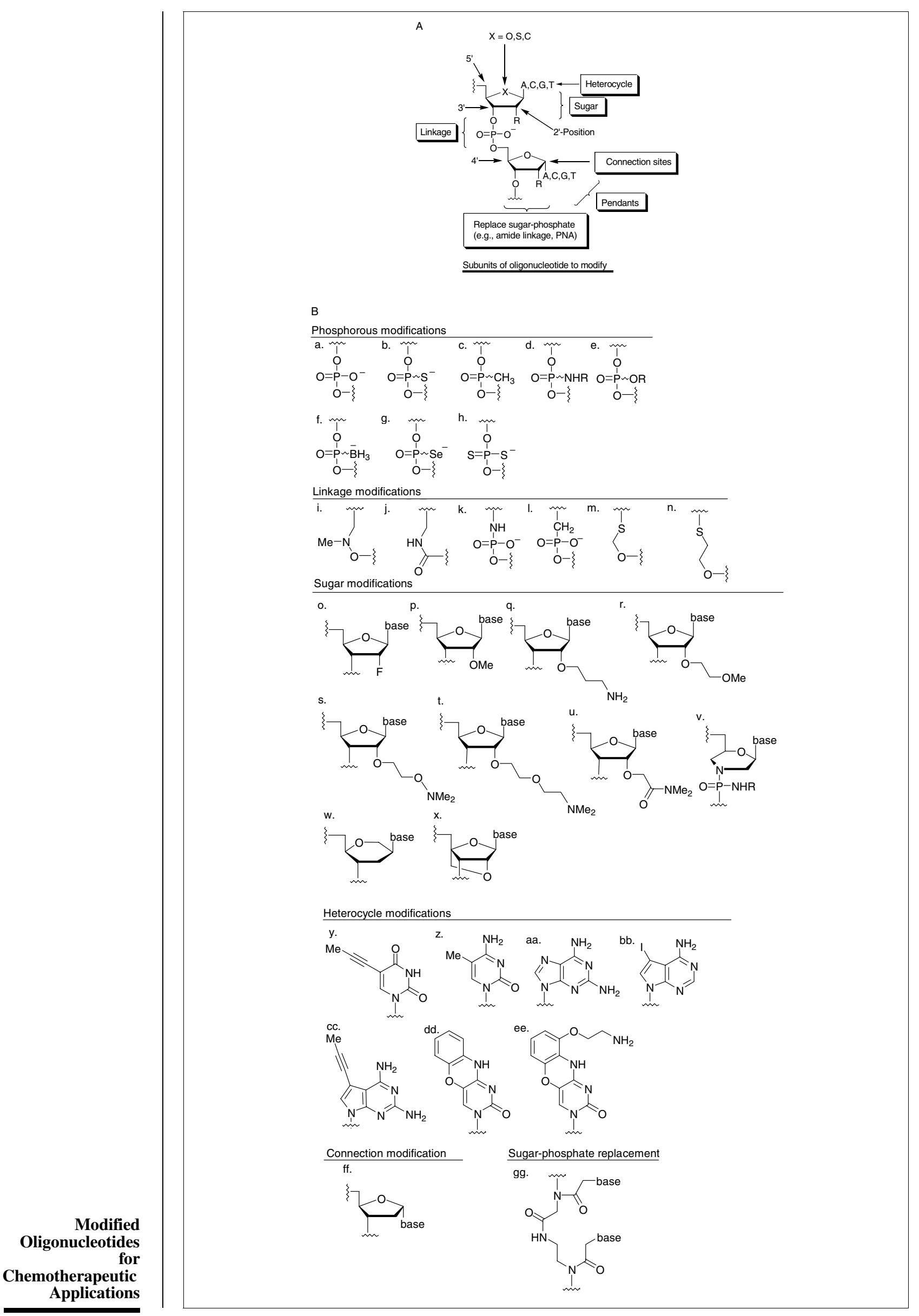


Oligonucleotides may also inhibit gene expression at the DNA level by several antigene approaches. The most often examined approach is triple strand formation by oligonucleotides binding in the major groove of dsDNA via several Hoogsteen base-pairing rules (Helene, 1993). A less often examined approach is the use of oligonucleotides to bind via Watson-Crick base-pairing rules to a single strand of DNA available from the formation of a transcription bubble or locally open-chain site of dsDNA.

Utilizing nucleic acids as decoys to compete with natural cis-acting sites on dsDNA for essential regulatory proteins is referred to as the sense approach. In this case, synthetic oligonucleotides (typically dsDNA) are designed to bind to proteins in a sequence-specific manner.

In another protein-binding approach, aptamers, derived from nucleic acid selection processes (see Chapter 9), can specifically target regulatory proteins. Common steps to all selection methods for nucleic acid-binding species are: (1) generation of a large pool of sequence diversity from chemically synthesized DNA pools, (2) transformation of the pools by enzymatic manipulations such as polymerase chain reaction (PCR) or in vitro transcription, (3) selection of functional shapes, and (4) amplification. As each RNA sequence folds into a distinct three-dimensional shape, and because of the large number of structures (millions) generated, complementary binding to a protein target may occur, providing useful biological properties (reviewed by Bacher and Ellington, 1998).

Of those drug discovery approaches based on oligonucleotides, the antisense efforts are clearly the most advanced, in that twenty three first-generation phosphorothioate oligonucleotides have entered human clinical trials and one antisense oligonucleotide has achieved FDA approval (Table 4.1.4). Much less success has been accomplished by targeting DNA with triple-strand-forming oligonucleotides, antisense ribozymes, and RNase L-modified oligonucleotides. From a chemical point of view, these and other less successful approaches listed in Tables 4.1.1 and 4.1.2 suffer from not being amenable to the readily available, firstgeneration backbone-modified oligonucleotides such as methylphosphonates, amidates, phosphorothioates, and $\alpha$ oligomers (Fig. 4.1.4B). Success in these drug discovery approaches, assuming that the biological rationale is valid, will require much more intensive chemical efforts.

\section{MODIFICATIONS AND DRUG PROPERTY ALTERATIONS}

A diverse range of modifications at all possible modification sites of an oligonucleotide have been reported (reviewed in Cook, 1998a). Figure 4.1.4A illustrates a dimer of an oligonucleotide depicting possible modifications for enhancing oligonucleotide drug properties. These include alterations of heterocycles, carbohydrates, linkages (backbones), and connection and conjugation sites, as well as the complete removal of the sugar-phosphate backbone. Most of the positions available in a GC or AT dimer ( 26 positions for each dimer) that do not directly interfere with Watson-Crick base-pair hydrogen bonding have been modified at one time or another.

The nucleobases or heterocycles of nucleic acids provide the recognition points for Watson-Crick base pairing and must maintain this specific interaction in any modification. Thus, the scope of heterocyclic modifications is quite limited; this is verified by the fact that only five or six modified heterocycles have demonstrated useful oligonucleotide drug properties. These can be characterized as lipophilic modifications at $\mathrm{C} 5$ of pyrimidines and $\mathrm{C} 7$ of 7 deazapurines. Enhanced stacking has been suggested to be the reason for increased binding

Figure 4.1.4 Oligonucleotide modification. (A) Dimer structure showing potential modification sites. (B) Examples of oligonucleotide modifications: (a) natural phosphate diester; (b) chiral phosphorothioate; (c) chiral methyl phosphonate; (d) chiral phosphoramidate; (e) chiral phosphate triester; (f) chiral boranophosphate; (g) chiral phosphoroselenoate; (h) phosphorodithioate; (i) methylenemethylimino (MMI); (j) 3'-amide; (k) 3' achiral phosphoramidate; (I) $3^{\prime}$ archiral methylene phosphonate; (m) thioformacetal; (n) thioethyl ether; (o) 2'-fluoro; (p) 2'-O-methyl; (q) 2'-O-(3amino)propyl; (r) 2'-O-(2-methoxy)ethyl; (s) 2'-O-2-( $N, N$-dimethylaminooxy)ethyl (DMAOE); (t) 2'$\mathrm{O}-2$-[2-( $N, N$-dimethylamino)ethyloxy]ethyl (DMAEOE); (u) 2'-O-N,N-dimethylacetamidyl; (v) $\mathrm{N}$-morpholinophosphordiamidate; (w) hexose nucleic acid; (x) locked nucleic acid (LNA); (y) 5-propynyluracil-1-yl; (z) 5-methylcytosin-1-yl; (aa) 2-aminoadenin-9-yl; (bb) 7-deaza-7-iodoadenin-9-yl; (cc) 7-deaza-7-propynyl-2-aminoadenin-9-yl; (dd) phenoxazinyl; (ee) phenoxazinylG-clamp; (ff) $\alpha$-deoxyribofuranosyl; (gg) peptide nucleic acid (PNA). See Cook (1999).

Synthesis of Modified Oligonucleotides and Conjugates 
affinity with this type of heterocycle modification. 2-Aminoadenine represents another type of modification that provides enhanced binding affinity. In this case, an additional hydrogen bond is formed to uracil, providing significant increases in melting temperature $\left(T_{\mathrm{m}}\right)$. All of these modifications-positioned to lie in the major or minor groove of the heteroduplex-do not affect sugar conformation of the heteroduplex, and do not provide useful nuclease resistances, but will support an RNase $\mathrm{H}$ cleavage mechanism.

Modifications in the ribofuranosyl moiety have provided the most value in the quest to enhance oligonucleotide drug properties. In particular, certain $2^{\prime}-O$ modifications have greatly increased binding affinity, increased nuclease resistance, and altered pharmacokinetics, and are potentially less toxic than phosphorothioate oligonucleotides (Cook, 1998a). Preorganization of the sugar into a 3 '-endo pucker conformation is responsible for the increased binding affinity. Unfortunately, no sugar modification has been reported that is useful in supporting RNase $\mathrm{H}$ cleavage.

Linkage or backbone modifications involve changes to the nonbridging oxygen atoms, such as phosphorothioate $(\mathrm{P}=\mathrm{S})$, methylphosphonate (Me-P), phosphoramidate (N-P), and others shown in Figure 4.1.4B, as well as extensive changes in which the entire four-atom linkage between sugar moieties is replaced. The most useful linkage-replacement modification, MMI (Fig. 4.1.4B), provides greatly enhanced binding affinities, removes the nuclease-cleavable phosphodiester linkage and the chirality of the phosphorothioate linkage, and allows adjustments of oligonucleotide lipophilicity by controlling the negative charge. Of the linkage changes, only phosphorothioates induce RNase H cleavage.

Several examples of connection modifications in oligonucleotides are $\alpha$-nucleoside linkage (reverse connection of the heterocycle at $\left.\mathrm{C} 1^{\prime}\right)$ and $\left(2^{\prime}-5^{\prime}\right)$-phosphodiester bonds (in place of the normal $\left(3^{\prime}-5^{\prime}\right)$-phosphodiester bond). Peptide nucleic acid (PNA) is an example of the complete removal of the sugar-phosphate backbone and replacement with a peptide linkage. In addition to the above modifications, pendants or conjugation groups can be attached at many positions in the various subunits to enhance drug properties.

The antisense concept implies well-defined structural requirements for the oligonucleotide ligand that binds to a reasonably characterized RNA receptor. Although this knowledge of rather precise binding is of great value and certainly sets this drug discovery approach apart from current approaches, additional modifications are limited to modifications that do not interfere with Watson-Crick basepairing rules.

Modifications of oligonucleotides may be expected to address essentially every facet of antisense drug properties. Biophysical and biochemical properties that may be affected by modifications include binding affinity, basepair specificity, nuclease resistance, chemical stability, lipophilicity, solubility, endonucleolytic cleavage of the RNA of a heteroduplex, biological pharmacokinetic properties, toxicological properties, and pharmacological properties. Drug properties that will be affected by altering biophysical and biochemical parameters include the general areas of pharmacokinetics, pharmacodynamics, and toxicology. In addition, certain modifications may represent cost and proprietary patent advantages.

Modifications of short strands of DNA and RNA for drug purposes should be rationally directed by drug property deficiencies of the parent or first-generation oligonucleotides (Table 4.1.5). Biological deficiencies are exposed by pharmacologic, pharmacokinetic, and toxicologic studies of the parent oligonucleotides at the biophysical, biochemical, in vitro, in vivo, and clinical levels. In addition, as modified oligonucleotides move from discovery into the development pipeline, chemical development deficiencies in, for example, larger-scale synthesis, purification, and analytical processes will emerge that must be resolved. Finally, in contemplating research in oligonucleotides, one should search the patent literature in addition to examining the traditional scientific literature, as considerable proprietary positions of various aspects of the technology have been achieved. Hopefully, the days of incorporating nucleosides, novel or known, into oligonucleotides based merely on availability are over. This nonrational approach was of value in the beginning of oligonucleotide structure-activity modifications simply to develop an information base. Now that more knowledge is available about what is required to achieve enhanced properties, current and future oligonucleotide modifications and studies of their structure-activity relationships should be soundly and rationally based on the need to resolve one or more of the deficiencies listed in Table 4.1.5, or to overcome emerging drug process or production problems. 
Table 4.1.5 Limitations of First-Generation $\mathrm{P}=\mathrm{S}^{a}$ Oligonucleotides

\begin{tabular}{ll}
\hline Area & Limitation \\
\hline Pharmacodynamics & Low affinity per nucleotide unit: \\
& low potency \\
& limited sites to target \\
& Inhibition of RNase H at high concentrations \\
& RNase H mechanism implicated \\
& Limited oral bioavailability \\
& Limited blood-brain barrier penetration \\
Pharmacokinetics & Dose-dependent pharmacokinetics \\
& Release of cytokines \\
Toxicologics & Complement-associated effects on blood pressure? \\
& Clotting effects \\
& Accumulation in kidneys? \\
\hline${ }^{\mathrm{P}=\mathrm{S}, \text { phosphorothioate. }}$ &
\end{tabular}

\section{OPTIMIZATION OF BINDING AFFINITY AND NUCLEASE RESISTANCE}

\section{Oligonucleotide Binding Affinities}

Based on the ligand-receptor theory of pharmacological activity, increasing the affinity of an oligonucleotide for its RNA target should increase potency. A relatively simple physicochemical experiment is employed to determine the level of binding and specificity of a modified oligonucleotide. A complementary oligonucleotide is the simplest target to which an antisense oligonucleotide can hybridize. Thus, using length-matched complementary oligonucleotides at stoichiometric concentrations in a medium that mimics the intracellular environment as closely as possible (salt, $\mathrm{pH}$, temperature, concentration), melting curves are employed to determine how tightly a modified oligonucleotide binds to its complement. This involves a spectrophotometric analysis to measure absorbance versus temperature. The melting temperature $\left(T_{\mathrm{m}}\right.$ - the temperature at which the mixture is half duplex and half single-stranded) is determined (Freier et al., 1992). Oligonucleotide affinity, as measured by melting curves, increases with the length of the oligonucleotide-RNA heteroduplex. Thus, 15to 25-mers are typically used in antisense experiments rather than shorter oligonucleotides, which may have $T_{\mathrm{m}}$ values close to or below physiological temperature and, therefore, may only form low levels of the required heteroduplex.

A few short oligomers (12-mers or less) have exhibited interesting biological activity, and these require modifications leading to high affinity per nucleotide unit. One interesting example was the report of potent and selective inhibition of gene expression by phosphorothioates (7- and 8-mers) containing only 5-propynyl-substituted uracil and cytosine bases (Fig. 4.1.4B; Wagner et al., 1996). Furthermore, several recent studies correlate binding affinities of a series of $2^{\prime}$ - $O$-modified oligonucleotides with increased in vitro and in vivo activity (Kawasaki et al., 1993; Morvan et al., 1993; Monia et al., 1993, 1996; Altmann et al, 1996a,b,c, 1997). An extensive comparative listing of binding affinities of 2 '- $O$ modifications was provided by Freier and Altmann (1997).

\section{Oligonucleotide Nuclease Resistance}

A number of in vivo pharmacokinetic studies in several animal species indicate that $\mathrm{P}=\mathrm{S}$ oligonucleotides are not as stable as initially thought (Zhang et al., 1996; Nicklin, 1998). Although the stability of $\mathrm{P}=\mathrm{S}$ oligonucleotides may be sufficient for many drug applications, greater stability will be helpful in expanding dosage regimens (longer duration of action relates to less frequent dosing) and in developing oral bioavailability. Additionally, less degradation of modified oligomers will minimize metabolite toxicity. In summary, the preponderance of published antisense biological data suggests that oligonucleotides with higher binding affinities and greater stabilities towards nucleases are important medicinal chemistry objectives.

\section{STANDARDS ESTABLISHED BY RECENT SAPR STUDIES}

The intense oligonucleotide research performed in the 1990s has provided a remarkable enhancement of several of the desired antisense
Synthesis of Modified Oligonucleotides and Conjugates 
drug properties. The results achieved with modified oligonucleotides concerning binding affinity, base-pair specificity, nuclease resistance, and support of RNase $\mathrm{H}$ cleavage of the targeted RNA is impressive. One should consider the level of binding affinity (as represented by $T_{\mathrm{m}}$ ), nuclease resistance (as represented by $t_{1 / 2}$ ), and support of an RNase $\mathrm{H}$ mechanism that a new modification should possess in order to be of interest as a potential drug. A number of "winners" have been identified (Fig. 4.1.4B) and discussed in several reviews (Cook, 1998a,b).

Certain modifications of oligonucleotides provide an increase in $T_{\mathrm{m}}$ of $>1.5^{\circ} \mathrm{C} /$ modification $\left({ }^{\circ} \mathrm{C} / \mathrm{mod}\right)$ relative to a $\mathrm{P}=\mathrm{S}$ oligonucleotide $\left(\sim 1.0^{\circ} \mathrm{C} / \mathrm{mod}\right.$ relative to an unmodified $\mathrm{P}=\mathrm{O}$ oligonucleotide), and nuclease resistance $\left(t_{1 / 2}\right)$ of $>24 \mathrm{hr}$ with snake venom phosphorodiesterase (SVPD; about the same as for $\mathrm{P}=\mathrm{S}$ ). In view of these values, the author suggests that a novel modification should exhibit a $T_{\mathrm{m}}$ $>1.5^{\circ} \mathrm{C} / \bmod$ compared to its $\mathrm{P}=\mathrm{S}$ oligonucleotide parent. In evaluation of binding properties, the modified oligonucleotides should be hybridized with an RNA complement, as this is the receptor required for the antisense approach. A clear correlation between $T_{\mathrm{m}}$ values derived from hybridization to a DNA complement or to an RNA has not been established. Also, correlations of $T_{\mathrm{m}}$ values have not been established for oligonucleotides having just one modification (point or pendent modification) or several modifications distributed throughout the sequence, or for those having a contiguous placement of the modification in the sequence (Cook, 1991; Lesnik et al., 1993; Buhr et al., 1996; Matteucci and Krosigk, 1996). Since the application of a modification will likely require its uniform placement in the sequence, or at least several contiguous bases in a row for a gapmer strategy (described below, Cook, 1993), binding affinity measurements $\left(T_{\mathrm{m}}\right)$ should be taken with these types of modified oligonucleotides. Furthermore, the modification must not compromise base-pair specificity. In this regard, information from a number of papers suggests that base-pair specificity actually increases as $T_{\mathrm{m}}$ values are increased. A specificity that is comparable to base mismatches of a $\mathrm{P}=\mathrm{S}$ phosphorothioate would appear to be a useful standard.

Nuclease resistance of a novel modification in a $\mathrm{P}=\mathrm{O}$ oligonucleotide backbone should at least be at the level of uniformly modified $\mathrm{P}=\mathrm{S}$ oligonucleotides. Given that measurements of $t_{1 / 2}$ values, unlike $T_{\mathrm{m}}$ measurements, are deter- mined using several procedures (e.g., by incubation with heat-inactivated fetal bovine serum, purified enzymes such as SVPD, cell or tissue extracts; or by in vivo dosing followed by extraction and analysis) under different conditions, the use of $\mathrm{P}=\mathrm{S}$ oligonucleotide controls (standards) is necessary. In addition, several concentrations of nuclease should be employed to identify and minimize complications leading to enzyme inhibition (Cummins et al., 1995). Half-lives of $\sim 24 \mathrm{hr}$ are often reported for $\mathrm{P}=\mathrm{S}$ oligonucleotides in SVPD assays. When the 3' end of an oligonucleotide is modified to have sufficient resistance to $3^{\prime}$-exonucleases, endonucleolytic cleavage becomes evident. Thus, modifications should also protect against endonucleases. In a gapmer strategy, this is accomplished by a phosphorothioate gap, which will also support an RNase H cleavage mechanism. Nuclease resistance of a modified oligomer, if not provided by the modification, may in many cases be enabled by employing a $\mathrm{P}=\mathrm{S}$ oligonucleotide backbone.

In considering the relative importance of the nuclease resistance of an antisense oligomer and its affinity level for its RNA target, recent biological results suggest that it may be more important to enhance the stability of an oligonucleotide than its binding affinity (Crooke et al., 1996a). Modifications that provide highbinding oligonucleotides with low nuclease resistance have not provided significant biological activity, whereas oligonucleotides such as phosphorothioates have. Although some modifications provide high binding affinities and high nuclease resistance, they may not exhibit useful antisense activities because they do not support an RNase $\mathrm{H}$ mechanism. A modification that supports an RNase $\mathrm{H}$ mode of action and provides high $T_{\mathrm{m}}$ and nuclease resistance $t_{1 / 2}$ values has not been reported. Thus, an ideal oligonucleotide modification would provide an oligomer that hybridizes to target RNA with high binding affinity and specificity, would be stable to nucleolytic degradation, and would allow RNase $\mathrm{H}$ cleavage of the RNA target. This has led to the theory that to optimize the antisense activity of an oligomer, a combination of oligonucleotide modifications will be required (Cook, 1991, 1993).

As noted above, after high-binding, nuclease-resistant $2^{\prime}$ - $O$-modified oligonucleotides were developed, it was rather disappointing that oligomers uniformly modified were inactive or less active than their first-generation parent phosphorothioates. It is now well known that uniformly $2^{\prime}$ - $O$-modified oligonucleotides do 
not support RNase H cleavage: the 2'-O-modified oligonucleotide-RNA heteroduplex presents a structural conformation that is recognized by the enzyme but is not cleaved (Crooke et al., 1995; Lima and Crooke, 1997). This lack of activity has led to the development of a chimeric strategy (gapmer technology; Cook, 1993; Monia et al., 1993; Yu et al., 1996).

This approach focuses on the design of highbinding, nuclease-resistant antisense oligonucleotides that are "gapped" with a contiguous sequence of 2'-deoxyribonucleoside phosphorothioates (2'-deoxy/PS)(Fig. 4.1.5). On hybridization to target RNA, a heteroduplex is presented that supports RNase $\mathrm{H}$ cleavage of the RNA strand. The stretch of the modified oligonucleotide-RNA heteroduplex that is recognized by RNase H may be placed anywhere within the modified oligonucleotide. The modifications in the flanking regions of the gap should not only provide nuclease resistance to exo- and endonucleases, but should also not compromise binding affinity and base-pair specificity (Hoke et al., 1991).

Modifications of the phosphorus atom of the natural phosphodiester linkage (producing methylphosphonates, phosphorothioates, and phosphoramidates) destabilize heteroduplexes $-0.7^{\circ}$ to $-1.5^{\circ} \mathrm{C}$ per modification (Fig. 4.1.4B; Agrawal et al., 1990; Dagle et al., 1991; Guinosso et al., 1991). The decreased binding affinity of these modified oligonucleotides could be expected to reduce antisense effectiveness. In the case of chimeric 2'-O-methyl- or 2'fluoro-modified oligonucleotides, an enhancement in the binding affinity of $\sim 2.0^{\circ}$ to $2.3^{\circ} \mathrm{C}$ (compared to $\mathrm{P}=\mathrm{S}$ oligonucleotides) for each modification is obtained (Sproat et al., 1989; Guinosso et al., 1991; Miller et al., 1991; Kawasaki et al., 1993). However, it is now clear that 2'-O-methyl- and 2'-F-modified DNA are not sufficiently nuclease resistant to have antisense value as $\mathrm{P}=\mathrm{O}$ backbones (Sproat et al., 1989; Morvan et al., 1993; Sproat and Lamond, 1993; Sands et al., 1995; Prasmickaite et al., 1998). The potential problem in this area can be circumvented by the use of 2'-O-methyl- or $2^{\prime}$-F-modified phosphorothioates in the flanking regions (doubly modified; Miller et al., 1991; Kawasaki et al., 1993).
More recent research has focused on $2^{\prime}-O$ modifications such as methoxyethyl (Altmann et al., 1996a,b,c) and aminopropyl (Griffey et al., 1996), which not only provide relatively high binding affinities but also a level of nuclease resistance that allows replacement of thiophosphates with natural phosphodiester linkages. With a favorable combination of $T_{\mathrm{m}}$ and $t_{1 / 2}, 2^{\prime}-O$ modifications can be employed in the chimeric strategy (gapmer technology; Fig. 4.1.5), which allows a significant portion of $\mathrm{P}=\mathrm{S}$ linkages to be replaced with $\mathrm{P}=\mathrm{O}$ linkages. Just how many sulfurs can be replaced depends on the length of the oligomer and the gap size or RNase H cleavage site. Typically, a 21-mer with a 7-nucleotide gap has $65 \%$ of the $\mathrm{P}=\mathrm{S}$ linkages replaced with $\mathrm{P}=\mathrm{O}$ linkages. As noted in the discussion of limitations of $\mathrm{P}=\mathrm{S}$ oligonucleotides, reduction of the sulfur content in a $\mathrm{P}=\mathrm{S}$ oligonucleotide could have important implications in the pharmacokinetic and pharmacodynamic properties as well as the toxicity profiles of oligonucleotides (Altmann et al., 1996a).

A very important aspect of gapmer technology is that the gap or RNase H cleavage site must be protected from endonucleolytic cleavage. Phosphodiester linkages and even an alternating $\mathrm{P}=\mathrm{S} / \mathrm{P}=\mathrm{O}$ motif do not provide a useful level of nuclease resistance for biological activity (Dagle et al., 1991; Hoke et al., 1991). The recently reported lack of activity of a "gapped" 3'-amidate phosphodiester is likely due to endonuclease degradation (Heidenreich et al., 1997). Phosphorothioates are the only useful modification to allow a reasonable combination of binding affinity and nuclease resistance and also support an RNase $\mathrm{H}$ mechanism. Hence, as noted above, most antisense activities require an RNase $\mathrm{H}$ mechanism, which in turn requires sulfur in the form of thiophosphate somewhere in the chimeric molecule for nuclease resistance.

An additional issue that should be kept in mind is the impact that oligonucleotide modifications may have on the cost of future antisense drugs. Again, as a standard, the cost of $\mathrm{P}=\mathrm{S}$ oligonucleotides should be considered. The cost of phosphorothioates has been dramatically reduced due to improvements in the process, cost reduction of key reagents, and eco-

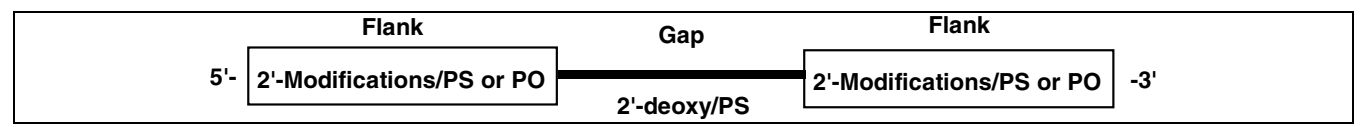

Figure 4.1.5 Gapmer technology. PO, phosphodiester; PS, phosphorothioate.
Synthesis of Modified Oligonucleotides and Conjugates

Current Protocols in Nucleic Acid Chemistry 
nomics of larger-scale syntheses. As of 1999, the cost of materials for a 20 -mer $\mathrm{P}=\mathrm{S}$ oligonucleotide was $<\$ 300 /$ gram; it is projected to decline to $<\$ 50 /$ gram as larger quantities are required. The $2^{\prime}$ - $O$-methoxyethyl-modified oligonucleotides are derived from ribonucleosides and should eventually be substantially less expensive than modified oligonucleotides derived from deoxyribofuranosyl nucleosides. $\mathrm{P}=\mathrm{S}$ oligonucleotide antisense drugs are expected to be cost competitive when considering parenteral (intravenous) treatment three times/week with a $1 \mathrm{mg} / \mathrm{kg}$ dose. Modified oligonucleotides must be cost effective and will need to be less expensive to synthesize (e.g., shorter), or provide a greater therapeutic index (increased potency) or other important advantages to offset an increase in the cost of synthesis.

When considering research to modify oligonucleotides, the author believes it is important to know the extent to which proprietary protection of a modification can be obtained. Important patent positions for many types of modifications have been established during the 1990s as designing drugs from oligonucleotides has become of interest (Crooke et al, 1996b; Sheffery and Gordon, 1996; Craig et al., 1997).

\section{GENERAL GUIDELINES FOR ENHANCING OLIGONUCLEOTIDE DRUG PROPERTIES}

The excitement roused by the prospect of using oligonucleotides as drugs stems from the fact that, unlike other drug discovery approaches, they are informational materialsi.e., chemicals having a specific set of rules (the Watson-Crick base-pairing rules) that clearly govern their binding to a specific nucleic acid receptor. In addition, the fact that DNA and RNA molecules are, compared to proteins, relatively new molecular targets is of great interest.

The first test in a SAPR study to determine whether a modified oligonucleotide is worth pursuing is whether it maintains its sequence specificity according to Watson-Crick rules (Fig. 4.1.6). A newly modified oligonucleotide that does not possess an acceptable level of specificity (comparable to that of the $\mathrm{P}=\mathrm{S}$ oligonucleotide) is an immediate failure. The next step is to determine how tightly the modified oligonucleotide binds to its target nucleic acid. As noted, the binding affinity of a modified oligomer is a physicochemical property, determined by measuring the oligomer's sequence- specific interaction with its length-matched RNA complement. The hybridization or melting process is performed under a rather standard set of conditions designed to mimic an intracellular environment (Freier et al., 1992). Because this calculation is done under artificial conditions, it may not accurately represent the binding of an oligomer to a native RNA inside a cell.

The next essential property of an oligonucleotide is sufficient resistance to degradation by exo- and endonucleolytic plasma and tissue nucleases (Fig. 4.1.6). Nuclease resistance is determined in various assays, such as incubating the oligonucleotide in heat-inactivated fetal bovine serum, cellular extracts, or purified exonucleases or endonucleases (also see Standards Established by Recent SAPR Studies). These results are also likely to differ from the stability of an oligomer in vivo. However, these $T_{\mathrm{m}}$ and $t_{1 / 2}$ assays do allow SAPR studies to proceed, and thus provide reasonable methods to compare various oligonucleotide modifications at an early developmental stage. This is quite different from traditional drug discovery approaches.

\section{CONJUGATED OLIGONUCLEOTIDES}

The sugar, heterocycle, and backbone (linkage) subunit modifications as depicted in Figure 4.1.4A are core modifications that greatly enhance binding affinities and nuclease resistance of antisense oligonucleotides. To enhance other antisense drug properties of an optimized, core-modified oligonucleotide, a variety of molecules (pendants) have been attached (conjugated) in a point-modification motif (i.e., only one pendant in an antisense oligonucleotide). Pendant modifications have primarily been directed to enhancing oligonucleotide uptake. Other potential applications of pendants include increased solubility, lipophilicity, and means to attach synthetic cleaving agents, intercalators (for improvements in binding affinity), and cross-linking and alkylating groups (see UNITS $4.2 \& 4.3)$. Several reviews have discussed oligonucleotide pendants (Cook, 1991, 1993; Manoharan, 1993; De Mesmaeker et al., 1995).

\section{PERSPECTIVE}

One $\mathrm{P}=\mathrm{S}$ oligonucleotide drug (Vitravene) is available as of 1999, and others will follow in the next several years. However, to continually improve this novel and exciting drug class, and to overcome certain limitations, structural changes are required. In the 1990s a diverse range of modifications, at all possible modifi- 


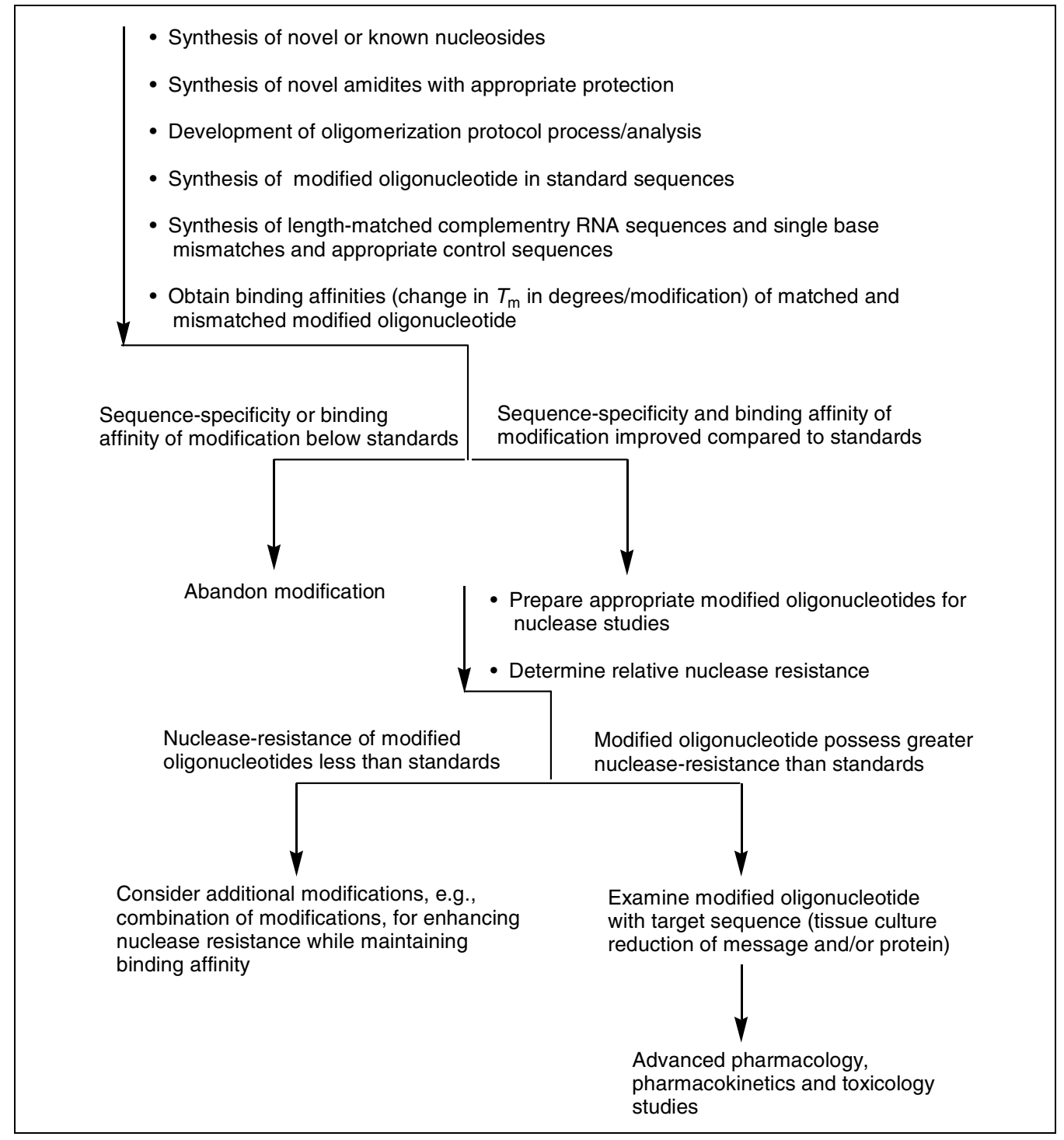

Figure 4.1.6 General pathway for structure-activity/property relationship studies.

cation sites of an oligonucleotide (Fig. 4.1.4A), has been reported. This application of traditional medicinal chemistry (SAPR studies) to drug discovery in antisense oligonucleotides, and in oligonucleotides in general, has answered many important questions. For example, as a result of this rather intense effort, modifications are now known that stabilize oligonucleotides towards nucleolytic degradation (e.g., 2'-O-methoxyethyl and 2'-O-aminopropyl), that greatly enhance binding affinities while maintaining base-pair specificity (e.g., 2 - $O$-methoxyethyl), and that support endonucleolytic cleavage by RNase H (e.g., 5propynyl pyrimidines). Although these are biochemical and biophysical properties, a large volume of cellular and animal studies support the notion that enhancing these properties correlates with enhanced antisense biological ac- tivity in vivo. Unfortunately, a single modification that provides high binding affinity nuclease-resistance and support of an RNase $\mathrm{H}$ mechanism is not available. A modification of this nature is of current interest in the antisense approach.

It is also known that changing the structure of phosphorothioate oligonucleotides provides an opportunity to alter their pharmacokinetic profile. Structural changes that remove sulfur (as thiophosphate) and/or change lipophilicity (e.g., by $2^{\prime}-O$ modifications) have resulted in more favorable toxicity profiles (Altmann et al., 1996a). Although research has revealed these important antisense properties (and there may be many more to learn about), and has shown how to control them, it has not yet determined the optimum values at which these modifications should be aimed. In addition, the lack of
Synthesis of Modified Oligonucleotides and Conjugates 
antisense oligonucleotides that are orally available and/or penetrate the blood-brain barrier represents the most important deficiency of antisense oligonucleotides. Recent reports of antisense $\mathrm{P}=\mathrm{S}$ oligonucleotides doubly modified at the $3^{\prime}$ and $5^{\prime}$ ends with $2^{\prime}-O$-methyl or $2^{\prime}$-O-methoxyethyl-to provide a high level of nuclease resistance- - have provided encouraging results suggesting that these pharmacokinetic deficiencies will soon be solved by appropriate chemical modifications (Agrawal et al., 1995).

One should be aware of the level of accomplishments achieved in oligonucleotide medicinal chemistry research in the course of the 1990s. Binding affinities, nuclease resistance, support of RNase $H$, and cost of synthesis have been discussed in this unit, and they should be considered (as standards) before initiating or continuing oligonucleotide modification research. In addition, understanding the proprietary patent positions that have been established is an important research consideration. The author believes that, at this stage of oligonucleotide medicinal chemistry, it is highly unlikely that a single modification will be discovered that will significantly affect all of the important drug properties described above. The types of modified oligonucleotides currently being pursued (going beyond $\mathrm{P}=\mathrm{S}$ oligonucleotides) possess a combination of modifications, and this trend will certainly continue as pendants will be conjugated to oligonucleotides with optimized core subunits to obtain a "completely" optimized oligonucleotide drug.

The current "winners," or the first modifications most likely to be incorporated into antisense oligonucleotides that will undergo clinical trials, are the RNA mimics 2'-Omethoxyethyl and $2^{\prime}$-O-aminopropyl, and the backbone modification MMI (Fig. 4.1.4B). These will likely be utilized in a gapmer strategy. However, efforts to prepare uniform modifications, such as RNA mimics $\left(2^{\prime}\right.$ - $O$-modifications), MMI, and PNA are of considerable interest, in that reliance on $\mathrm{RNase} \mathrm{H}$ for a mode of action would not be required. In addition to these modifications that act either by direct binding (RNase $\mathrm{H}$ independent) or via RNase $\mathrm{H}$, the author believes that subunit pendant modifications (such as cholesterol conjugates and folic acid conjugates) will become increasingly important for optimizing multiply modified oligonucleotides.

\section{LITERATURE CITED}

Agrawal, S., Mayrand, S.H., Zamecnik, P.C., and Pederson, T. 1990. Site-specific excision from RNA by RNase $\mathrm{H}$ and mixed-phosphate-backbone oligodeoxynucleotides. Proc. Natl. Acad. Sci. U.S.A. 87:1401-1405.

Agrawal, S., Zhang, X., Lu, Z., Zhao, H., Tamburin, J.M., Yan, J., Cai, H., Diasio, R.B., Habus, I., Jiang, Z., Iyer, R.P., Yu, D., and Zhang, R. 1995. Absorption, tissue distribution and in vivo stability in rats of a hybrid antisense oligonucleotide following oral administration. Biochem. Pharmacol. 50:571-576.

Alderfer, J.L., Loomis, R.E., Soni, S.D., Sharma, M., Bernacki, R., and Hughes, R. Jr. 1985. Halogenated nucleic acids: Biochemical and biological properties of fluorinated polynucleotides. Polymeric Mater. Med. 32:125-138.

Altman, S. 1989. Ribonuclease P: An enzyme with a catalytic RNA subunit. Adv. Enzymol. 62:1-36.

Altmann, K.H., Dean, N.M., Fabbro, D., Freier, S.M., Geiger, T., Häner, R., Hüsken, D., Martin, P., Monia, B.P., Müller, M., Natt, F., Nicklin, P., Phillips, J., Pieles, U., Sasmor, H., and Moser, H.E. 1996a. Second generation of antisense oligonucleotides: From nuclease resistance to biological efficacy in animals. Chimia 50:168-176.

Altmann, K.H., Kesselring, R., and Pieles, U. 1996b. 6'-Carbon-substituted carbocyclic analogs of 2'deoxyribonucleosides: Synthesis and effect on DNA/RNA duplex stability. Tetrahedron 52:12699-12722.

Altmann, K.H., Fabbrot, D., Dean, N.M., Geiger, T., Monia, B.P., Muller, M., and Nicklin, P. 1996c. Second-generation antisense oligonucleotides: Structure-activity/relationships and the design of improved signal-transduction inhibitors. Biochem. Soc. Trans. 24:630-637.

Altmann, K.H., Martin, P., Dean, N.M., and Monia, B.P. 1997. Second generation antisense oligonucleotides - inhibition of pkc- $\alpha$ and c-raf kinase expression by chimeric oligonucleotides incorporating 6 -substituted carbocyclic nucleosides and 2'-O-ethylene glycol substituted ribonucleosides. Nucleosides Nucleotides 16:917.

Bacher, J.M. and Ellington, A.D. 1998. Nucleic acid selection as a tool for drug discovery. Drug Discovery Today 3:265.

Bardos, T.J. and Ho, Y.K. 1978. Chemical and Enzymatic Methods in the Synthesis of Modified Polynucleotides. In Symposium on the Chemistry and Biology of Nucleosides and Nucleotides (R.E. Harmon, R.K. Robins, and L. Townsend, eds.) pp. 55-68. Academic Press, Orlando, Fla.

Belikova, A.M., Zarytova, V.F., and Grivneva, N.I. 1967. Synthesis of ribonucleosides and diribonucleoside phosphates containing 2-chloroethylamine and nitrogen mustard residues. Tetrahedron Lett. 7:3557-3562.

Buhr, C.A., Wagner, R.W., Grant, D., and Froehler, B.C. 1996. Oligodeoxynucleotides containing C-7 propyne analogs of 7-deaza-2'-deoxyguanosine and 7-deaza-2'-deoxyadenosine. Nucl. Acids Res. 24:2974-2980. 
Cech, T.R. 1986. RNA as an enzyme. Sci. Am. 255:64-75.

Chandra, P. and Bardos, T.J. 1972. Inhibition of DNA polymerases from RNA tumor viruses by novel template analogs. Partially thiolated polycytidylic acid. Res. Commun. Chem. Pathol. Pharmacol. 4:615-622.

Cohen, J.S. 1991. Informational drugs: A new concept in pharmacology. Antisense Res. Dev. 1:191-193.

Connell, C., Fung, S., Heiner, C., Bridgham, J. Chakarian, V., Heron, E., Jones, R., Menchen, S., Mordan, W., Raff, M., Recknor, M., Smith, L., Springer, J., Woo, S., and Hunkapiller, M. 1987. Automated DNA sequence analysis. BioTechniques 5:342.

Cook, P.D. 1991. Medicinal chemistry of antisense oligonucleotides - future opportunities. AntiCancer Drug Design 6:585-607.

Cook, P.D. 1993. Medicinal chemistry strategies for antisense research. In Antisense Research and Applications (S.T. Crooke and B. Lebleu, eds.) pp. 149-187. CRC Press, Boca Raton, Fla.

Cook, P.D. 1998a. Antisense medicinal chemistry. In Handbook of Experimental Pharmacology (S.T. Crooke, ed.) pp. 51-101. Springer-Verlag, Heidelberg, Germany.

Cook, P.D. 1998b. Second generation antisense oligonucleotides: 2'-Modifications. Annu. Rep. Med. Chem. 33:313.

Cook, P.D. 1999. Making drugs out of oligonucleotides: A brief review and perspective. $\mathrm{Nu}$ cleosides Nucleotides 18:1141-1162.

Craig, A., Vanstone, D., and Sudhir, A. 1997. Patent strategies in the antisense oligonucleotide based therapeutic approach. Expert Opin. Ther. 7:1175.

Crooke, S.T., Lemonidis, K.M., Neilson, L., Griffey, R., Lesnik, E.A., and Monia, B.P. 1995. Kinetic characteristics of Escherichia coli RNase H1: Cleavage of various antisense oligonucleotideRNA duplexes. J. Biochem. 312:599-608.

Crooke, S.T., Graham, M.J., Zuckerman, J.E., Brooks, D., Conklin, B.S., Cummins, L.L., Greig, M.J., Guinosso, C.J., Kornbrust, D., Manoharan, M., Sasmor, H.M., Schleich, T., Tivel, K.L., and Griffey, R.H. 1996a. Pharmacokinetic properties of several novel oligonucleotide analogs in mice. J. Pharmacol. Exp. Ther. 277:923-937.

Crooke, S.T., Bernstein, L.S., and Boswell, H. 1996b. Progress in the development and patenting of antisense drug discovery technology. $E x$ pert Opin. Ther. 6:855-870.

Cummins, L.L., Owens, S.R., Risen, L.M., Lesnik, E.A., Freier, S.M, McGee, D., Guinosso, C.J., and Cook, P.D. 1995. Characterization of fully 2'-modified oligoribonucleotide hetero- and homoduplex hybridization and nuclease sensitivity. Nucl. Acids Res. 23:2019-2024.

Dagle, J.M., Andracki, M.E., DeVine, R.J., and Walder, J.A. 1991. Physical properties of oligonucleotides containing phosphoramidate-modified internucleoside linkages. Nucl. Acids Res. 19:1805-1810.
De Clercq, E., Eckstein, F., and Merigan, T.C. 1969. Interferon induction increased through chemical modification of a synthetic polyribonucleotide. Science 165:1137-1139.

DeMesmaeker, A., Haner, R., Martin, P., and Moser, H.E. 1995. Antisense oligonucleotides. Acc. Chem. Res. 28:366-374.

Ellington, A.D. and Szostak, J.W. 1990. In vitro selection of RNA molecules that bind specific ligands. Nature 346:818-822.

Freier, S.M. and Altmann, K.-H. 1997. The ups and downs of nucleic acid duplex stability: Structure-stability studies on chemically-modified DNA: RNA duplexes. Nucl. Acids Res. 25:4429-4443.

Freier, S.M., Lima, W.F., Sanghvi, Y.S., Vickers, T., Zounes, M., Cook, P.D., and Ecker, D.J. 1992. Thermodynamics of antisense oligonucleotide hybridization. In Gene Regulation: Biology of Antisense RNA and DNA, Vol. 1 (Series: Molecular Cellular Biology) (R.P. Erickson and J.G. Izant, eds.) pp. 95-107. Raven Press, New York.

Griffey, R.H., Monia, B.P., Cummins, L.L., Freier, S., Greig, M.J., Guinosso, C.J., Lesnik, E., Manalili, S.M., Mohan, V., Owens, S., Ross, B.R., Sasmor, H., Wancewicz, E., Weiler, K., Wheeler, P.D., and Cook, P.D. 1996. 2'-O-aminopropyl ribonucleotides: A zwitterionic modification that enhances the exonuclease resistance and biological activity of antisense oligonucleotides. J. Med. Chem. 39:5100-5109.

Guinosso, C.J., Hoke, G.D., Freier, S.M., Martin, J.F., Ecker, D.J., Mirabelli, C.K., Crooke, S.T., and Cook, P.D. 1991. Synthesis and biophysical and biological evaluation of 2 '-modified antisense oliogonucleotides. Nucleosides Nucleotides 10:259-262.

Heidenreich, O., Gryaznov, S., and Nerenberg, M. 1997. RNase H-independent antisense activity of oligonucleotide N3'-P5' phosphorothioates. Nucl. Acids Res. 25:776.

Helene, C. 1993. Control of gene expression by triple-helix-forming oligonucleotides: The antigene strategy. In Antisense Research and Applications (S.T. Crooke and B. Lebleu, eds.) pp. 375-385. CRC Press, Boca Raton, Fla.

Hoke, G.D., Draper, K., Freier, S.M., Gonzalez, C., Driver, V.B., and Zounes, M.C. 1991. Effects of phosphorothioate capping on antisense oligonucleotide stability, hybridization and antiviral efficacy versus herpes simplex virus infection. Nucl. Acids Res. 19:5743.

Kawasaki, A.M., Casper, M.D., Freier, S.M., Lesnik, E.A., Zounes, M.C., Cummins, L.L., Gonzalez, C., and Cook P.D. 1993. Uniformly modified 2'-deoxy-2'-fluoro phosphorothioate oligonucleotides as nuclease-resistant antisense compounds with high affinity and specificity for RNA targets. J. Med. Chem. 36:831-841.
Synthesis of Modified Oligonucleotides and Conjugates

Current Protocols in Nucleic Acid Chemistry 
LeDoan, T., Perrouault, L., Praseuth, D., Habhoub, N., Decout, J.L., Thuong, N.T., Lhomme, J., and Helene, C. 1987. Sequence-specific recognition, photocrosslinking and cleavage of the DNA double helix by an oligo- $[\alpha]$-thymidylate covalently linked to an azidoproflavine derivative. Nucl. Acids Res. 15:7749.

Lesnik, EA., Guinosso, C.J., Kawasaki, A.M., Sasmor, H., Zounes, M., Cummins, L.L., Ecker, D.J., Cook, P.D., and Freier, S.M. 1993. Oligodeoxynucleotides containing $2^{\prime}$ - $O$-modified adenosine: Synthesis and effects on stability of DNA:RNA duplexes. Biochemistry 32:78327838.

Lima, W.F. and Crooke, S.T. 1997. Binding affinity and specificity of Escherichia coli RNase H1: Impact on the kinetics of catalysis of antisense oligonucleotide-RNA hybrids. Biochemistry 36:390-398.

Manoharan, M. 1993. Designer antisense oligonucleotides: Conjugation chemistry and functionality placement. In Antisense Research and Applications (S.T. Crooke and B. Lebleu, eds.) pp. 303-349. CRC Press, Boca Raton, Fla.

Matteucci, M.D. and von Krosigk, U. 1996. Hybridization properties of oligonucleotides bearing a tricyclic 2 -deoxycytidine analog based on a carbazole ring system. Tetrahedron Lett. 37:5057-5060.

Miller, P.S., Bhan, P., Cushman, C.D., Kean, J.M., and Levis, J.T. 1991. Antisense oligonucleotide methylphosphonates and their derivatives. $\mathrm{Nu}$ cleosides Nucleotides 10:37-46.

Monia, B.P., Lesnik, E.A., Gonzalez, C., Lima, W.F., McGee, D., Guinosso, C.J., Kawasaki, A.M., Cook, P.D., and Freier, S.M. 1993. Evaluation of 2 '-modified oligonucleotides containing 2 '-deoxy gaps as antisense inhibitors of gene expression. J. Biol. Chem. 268:14514-14522.

Monia, B.P., Johnston, J.F., Sasmor, H., and Cummins, L.L. 1996. Nuclease resistance and antisense activity of modified oligonucleotides targeted to Ha-ras. J. Biol. Chem. 271:1453314540.

Morishita, R., Givvons, G.H., Kaneda, Y., and Dzau, V.J. 1995. Pharmacokinetics of antisense oligodeoxynucleotides (cyclin B1 and cdc2 kinase) in the vessel wall in vivo: Enhanced therapeutic utility for restenosis by HVJ-liposome delivery. Gene 149:13-19.

Morvan, F., Porumb, H., Degols, G., Lefebvre, I., Pompon, A., Sproat, S., Rayner, B., Malvy, C., Lebleu, B., and Imbach, J.-L. 1993. Comparative evaluation of seven oligonucleotide analogues as potential antisense agents. J. Med. Chem. $36: 280-287$

Moser, H.E. and Dervan, P.B. 1987. Sequence-specific cleavage of double helical DNA by triple helix formation. Science 238:645-650.

Modified Oligonucleotides for Chemotherapeutic Applications

Nicklin, P. 1998. Pharmacokinetics properties of phosphorothioates in animals. In Handbook of Experimental Pharmacology (S.T. Crooke, ed.) pp. 141-168. Springer-Verlag, Heidelberg, Germany.
Prasmickaite, L., Hogset, A., Maelandsmo, G., Berg, K., Goodchild, J., Perkins, T., Fodstad, O., and Hovig, E. 1998. Intracellular metabolism of a 2'-O-methyl-stabilized ribozyme after uptake by DOTAP transfection or as free ribozyme. A study by capillary electrophoresis. Nucl. Acids Res. 26:4241-4248.

Rossi, J.J. 1998. Therapeutic ribozymes: Principles, applications, and problems. In Applied Antisense Oligonucleotide Technology (C.A. Stein and A.M. Krieg, eds.) pp. 511-525. Wiley-Liss, New York.

Sands, H., Gorey-Feret, L.J., Ho, S.P., Bao, Y., Cocuzza, A.J., Chidester, D., and Hobbs, F.W. 1995. Biodistribution and metabolism of internally $3 \mathrm{H}$-labeled oligonucleotides. II. 3',5'Blocked oligonucleotides. Therapeutics 47:636646.

Sheffery, M. and Gordon, C.L. 1996. Leadership positions in antisense patents (company report). Mehta and Isaly Equity Research, New York.

Sproat, B.S. and Lamond, A.I. 1993. 2'-O-Alkyloligoribonucleotides. In Antisense Research and Applications (S.T. Crooke and B. Lebleu, eds.) pp. 351-362. CRC Press, Boca Raton, Fla.

Sproat, B.S., Lamond, A.I., Beijer, B., and Neuner, U. 1989. Highly efficient chemical synthesis of 2 - $O$-methyloligoribonucleotides and tetrabiotinylated derivatives; novel probes that are resistant to degradation by RNA or DNA specific nucleases. Nucl. Acids Res. 17:3373-3386.

Stephenson, M.L. and Zamecnik, P.C. 1978. Inhibition of Rous sarcoma viral RNA translation by a specific oligodeoxyribonucleotide. Proc. Natl. Acad. Sci. U.S.A. 75:285-288.

Summerton, J. 1979. Intracellular inactivation of specific nucleotide sequences: A general approach to the treatment of viral diseases and virally-mediated cancers. J. Ther. Biol. 78:77-99.

Torrence, P.F., Xiao, W., Li, G., Lesnik, K., Khamnei, S., Maran, A., Maitra, R., Dong, B., and Silverman, R.H. 1994. 2',5'-Oligoadenylate antisense chimeras for targeted ablation of RNA in carbohydrate modifications. In Antisense Research (Y.S. Sanghvi and P.D. Cook, eds.) pp. 118-132. American Chemical Society, Washington, D.C.

Ts'o, P.O., Miller, P.S., Aurelian, L., Murakami, A., Agris, C., Blake, K.R., Lin, S.B., Lee, B.L., and Smith, C.C. 1987. An approach to chemotherapy based on base sequence information and nucleic acid chemistry. Matagen (masking tape for gene expression). Ann. N.Y. Acad. Sci. 507:220-241.

Tuerk, C. and Gold, L. 1990. Systematic evolution of ligands by exponential enrichment: RNA ligands to bacteriophage T4 DNA polymerase. Science 249:505-510.
Wagner, R.W., Matteucci, M.D., Grant, D., Huang, T., and Froehler, B.C. 1996. Potent and selective inhibition of gene expression by an antisense heptanucleotide. Nat. Biotechnol. 14:840-844. 
Yu, D., Iyer, R.P., Shaw, D.R., Lisziewicz, J., Li, Y., Jiang, Z., Roskey, A., and Agrawal, S. 1996. Hybrid oligonucleotides: Synthesis, biophysical properties, stability studies, and biological activity. Bioorg. Med. Chem. Lett. 4:1685-1692.

Zamecnik, P.C. and Stephenson, M.L. 1978. Inhibition of Rous sarcoma virus replication and cell transformation by a specific oligodeoxynucleotide. Proc. Natl. Acad. Sci. U.S.A. 75:280284.
Zhang, R., Iyer, R.P., Yu, D., Tan, W., Zhang, X., Lu, Z., Zhao, H., and Agrawal, S. 1996. Pharmacokinetics and tissue disposition of a chimeric oligodeoxynucleoside phosphorothioate in rats after intravenous administration. J. Pharmacol. Exper. Ther. 278:971-979.

Zon, G. 1993. History of antisense drug discovery. In Antisense Research and Applications (S.T. Crooke and B. Lebleu, eds.) pp. 1-5. CRC Press, Boca Raton, Fla.

Contributed by P. Dan Cook

Isis Pharmaceuticals

Carlsbad, California
Synthesis of Modified

Oligonucleotides and Conjugates 